\title{
Reevaluating claims of ecological speciation in Halichoeres bivittatus
}

\author{
Dan Warren ${ }^{1}$, Ron Eytan ${ }^{2}$, Alex Dornburg ${ }^{3}$, Teresa Iglesias ${ }^{1}$, Matt Brandley ${ }^{4}$, and Peter \\ Wainwright $^{5}$ \\ ${ }^{1}$ Okinawa Institute of Science and Technology Graduate University \\ ${ }^{2}$ Texas A\&M University at Galveston \\ ${ }^{3}$ University of North Carolina at Charlotte \\ ${ }^{4}$ Carnegie Museum of Natural History \\ ${ }^{5}$ University of California Davis
}

April 7, 2021

\begin{abstract}
Understanding the role of ecological processes in speciation has become one of the most active areas of research in marine population biology in recent decades. The traditional view was that allopatry was the primary driver of speciation in marine taxa, but the geography of the marine environment and the dispersal capabilities of many marine organisms render this view somewhat questionable. One of the earliest and most highly cited empirical examples of ecological speciation with gene flow in marine fishes is that of the slippery dick wrasse, Halichoeres bivittatus. Evidence for this cryptic or incipient speciation event was primarily in the form of a deep north-south divergence in a single mitochondrial locus, combined with a finding that these two haplotypes were associated with different habitat types in the Florida Keys and Bermuda, where they overlap. Here we examine habitat assortment in the Florida Keys using a broader sampling of populations and habitat types than were available for the original study, and find no evidence to support the claim that haplotype frequencies differ between habitat types, and little evidence to support any differences between populations. These results severely undermine claims of ecological speciation with gene flow in Halichoeres bivittatus. We argue that future claims of this type should be supported by multiple lines of evidence that illuminate potential mechanisms and allow researchers to rule out alternative explanations for spatial patterns of genetic differences.
\end{abstract}

\section{Hosted file}

Manuscript.pdf available at https://authorea.com/users/406313/articles/517020-reevaluatingclaims-of-ecological-speciation-in-halichoeres-bivittatus 


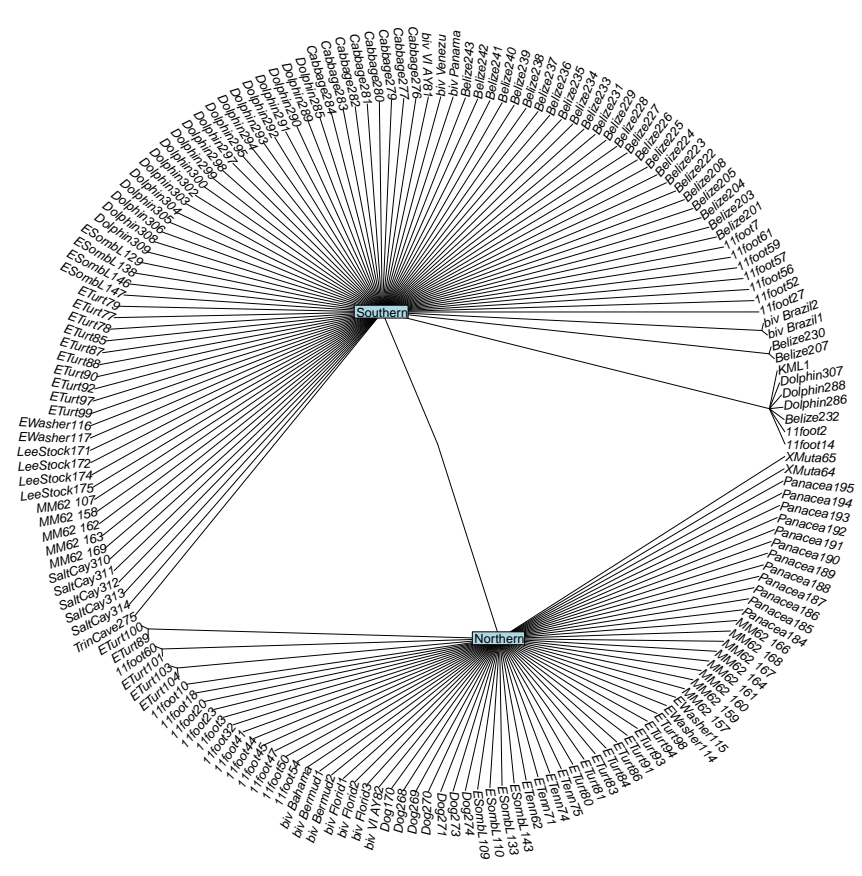



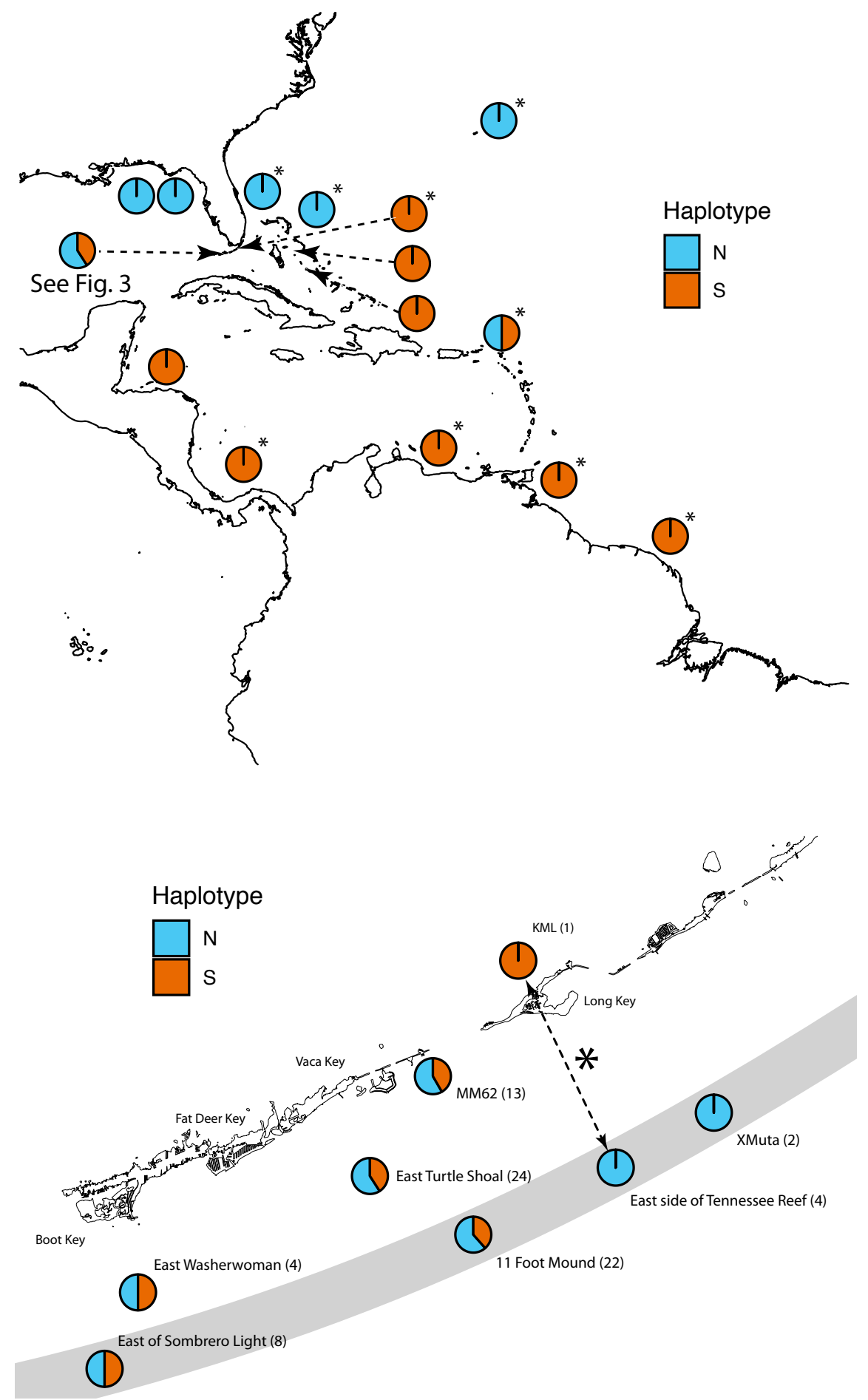


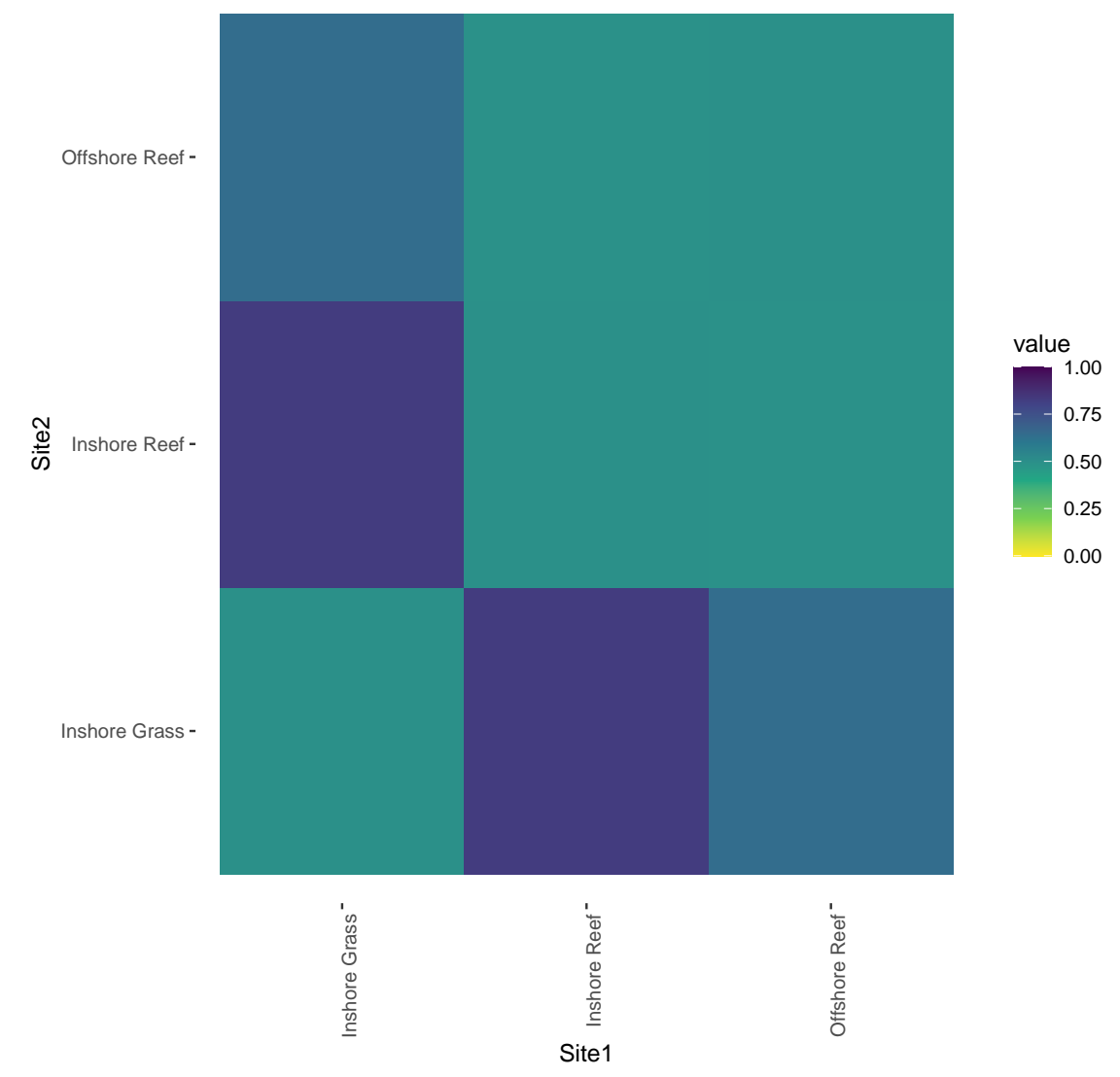




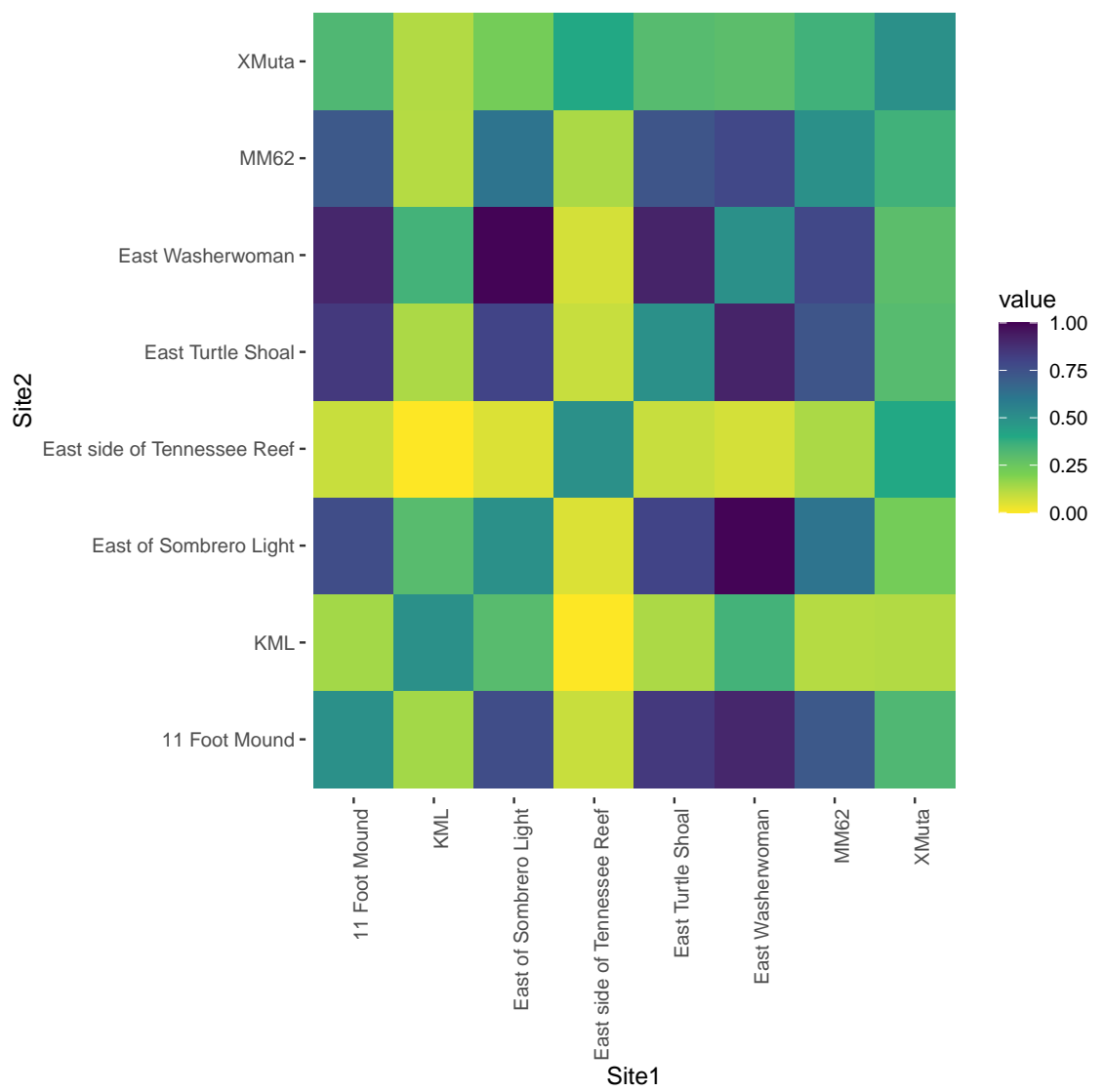

